\title{
ELECTRICAL CIRCUITS PROTECTION AGAINST UNDER VOLTAGE OR OVER VOLTAGE
}

\author{
Rama Rao Lachanna \\ Department of Mechanical Engineering \\ Politeknik Banting Selangor \\ Malaysia \\ Lawrence Arokiasamy \\ Q-FIT Sdn. Bhd. \\ Malaysia
}

\begin{abstract}
Designed circuit protects the AC line against disturbances and it operates by switching off the power supply upon detection of under voltage or over voltage conditions. When the AC line voltage drop to under voltage conditions or rise to over voltage conditions, the circuit will trigger the dual retriggerable monostable multivibrator and the circuit will be cut-off. The voltages correspond to a $15 \%$ under voltage warning, a $20 \%$ under voltage failure level and a $\mathbf{1 0 \%}$ over voltage failure level and this voltage compared by using a comparator before it trigger by the dual retriggerable monostable multivibrator. The $15 \%$ under voltage will give a warning condition by turning on a yellow LED and $20 \%$ under voltage or $10 \%$ over voltage failure conditions will turn $\mathrm{ON}$ a red LED. When the AC line voltage returns to its nominal level, the circuit will automatically resets a switch and reconnects the line voltage and it will turn $O N$ a green LED. This projects have successfully operates by switch off the power supply when there is an under voltage or over voltage condition.
\end{abstract}

Keywords - under voltage, over voltage, power quality

\section{INTRODUCTION}

Power quality is an issue that is becoming increasingly important to electricity consumers at all levels of usage [7]. Most people plug a device into an AC outlet without ever thinking about how it works and most of the time, everything work fine and no problems will experience. However, there are few things that are needed to release the problem that we have to face and what the protection needed. The purpose of protection equipment is to minimize the effects of faults on electric system, which unfortunately can never be entirely avoided and protection engineering is thus on extremely important part of the electrical [1]. Since the damage a fault can cause, is mainly dependent on its duration, it is necessary for the protection devices to operate as quickly as possible [2]. Voltage unbalance occurs in electrical system due to the asymmetry of the equipment on the one hand and the asymmetry of load states on the other [3]. Voltage unbalance on drive machines leads to increased losses on a synchronous machine; voltage unbalance of even $2 \%$ can lead to damaging temperature rises. Under voltage and over voltage can cause problem in an electrical system. Over voltage can be result of defective voltage regulators on generator or power transformer or of load shedding or poor power factor regulation. Over voltage can cause overheating and components failure due to voltage stress. Under voltage is mostly a consequence of a fault and it can cause loss of function, over heating, and erratic operation in some devices [4]. To solve this problem, a circuit that will protect the device from under voltage and over voltage will be used. This circuit will protect the ac line against disturbances and it operates by switching off the power supply upon detection of under voltage or over voltage conditions. When the ac line voltage returns to its nominal level, the circuit automatically reset a switch and reconnects the line voltage.

The main objectives of this study are as stated below.

a) To study what are the problem arise when the unbalance voltage happened and to test a circuit that can be used to protect the equipment against under voltage and over voltage.

b) To switch off the power supply upon detection of under voltage or over voltage condition by reducing the unbalanced voltage in the electric system.

\section{TESTING METHODS}

This project will be test in the lab using the circuit to analysis the under voltage and over voltage in equipment. The equipment in this project will be used lamb as the load. The testing method is divided to four tests that is: 


\section{International Journal of Engineering Applied Sciences and Technology, 2020 Vol. 4, Issue 11, ISSN No. 2455-2143, Pages 59-62 \\ Published Online March 2020 in IJEAST (http://www.ijeast.com)}

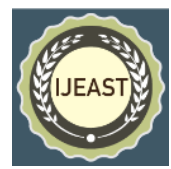

Test A: The circuit was tested by giving a normal voltage to the load.

Test B: The circuit was tested by giving $15 \%$ under voltage to the load. This $15 \%$ under voltage will give a warning condition by turning on a yellow LED.

Test C: The circuit was tested by giving $20 \%$ under voltage failure level to the load and failure conditions turn on a red LED and trigger the dual retriggerable monostable multivibrator.

Test D: The circuit was tested by giving $10 \%$ over voltage to the load. This $10 \%$

Over voltage will give a warning condition by turning on a yellow LED.

\section{ANALYSIS AND RESULTS}

\section{A. Analysis of the circuit}

In the voltage operation condition, the main voltage for the circuit will be given $240 \mathrm{~V}$ from the power supply and regulated $5 \mathrm{~V}$ supply. A voltage regulator is a circuit that provides a constant DC voltage level to its load. In this project, a $9 \mathrm{~V}$ battery is regulated to $5 \mathrm{~V}$ supply for the circuit. The input stage in the circuit a voltage divider, using $1 \mathrm{~K} \mathrm{ohm}$ potentiometer and then the circuit incorporates a IN 4001 rectifying diode, $100 \mathrm{~K}$ ohm resistor and a $10 \mu \mathrm{F}$ storage capacitor that provides low pass filtering to stabilize the AC supply voltage-comparison level to a DC supply. The potentiometer is adjusted so that the normal condition of the AC supply, $240 \mathrm{~V}$ corresponds to a 2.19 voltage - comparison level. This 2.19 voltage - comparison level is calculated by adjusting the potentiometer to minimum value and then to maximum value. This $2.19 \mathrm{~V}$ is an intermediate value between the minimum and maximum voltage. LM 339 comparator is used to verify the voltage comparison level and it is a device that consists of four independent voltage comparators that are designed to operate from a single power supply over a wide range of voltage. Voltage comparators are divided into two classification and they are the non-inverting and inverting comparator. In this operation, IC LM 339 pin 4, 7 and 9 are identified as a Vin and pin 5, 6 and 8 are identified as Vref. When the voltage is normal, Vin at pin 4, 7 and 9 will be adjusted to $2.19 \mathrm{~V}$ value and Vref for the pin 5, 6 and 8 is respectively at value $2.435 \mathrm{~V}, 1.832 \mathrm{~V}$ and $1.671 \mathrm{~V}$. The voltages correspond to a $15 \%$ under voltage warning, a $20 \%$ under voltage failure level and a $10 \%$ over voltage failure level. These comparison voltages correspond to AC supply voltages of $200 \mathrm{~V}, 185 \mathrm{~V}$ and $264 \mathrm{~V}$ respectively. The $15 \%$ under voltage warning condition turns in a yellow LED and failure conditions turn on a red LED and trigger the dual retriggerable monostable multivibrator (74HCT123). The fourth comparator of the LM339 produces a high frequency

square wave that continuously retriggers the monostable while the fault condition is present.

The dual retriggerable monostable multivibrator (74HCT123) is high-speed si-gate CMOS devices and is pin compatible with low power schottky TTL. Multivibrator can be defined as a transistor that can be used to generate continuous pulses or triggered or controlled pulses. The duration of the output pulse is independent of the duration of the input pulse because only the negative edge of the input pulse triggers the output pulse. In the dual retriggerable monostable multivibrator, the output of the first $\mathrm{IC}_{\mathrm{A}}$ is narrow and serves to define a time window that prevents sudden transient disturbances from triggering the second $\mathrm{IC}_{\mathrm{B}}$. Consequently, if the $\mathrm{AC}$ line voltage quickly returns to its nominal condition, the circuit does not disconnect the load. The output pulse width of the other monostable, which can be adjusted via the $50 \mathrm{kV}$ potentiometer, defines the time the load remains disconnected after the return of the nominal AC line voltage. When there is enough signal or voltage at the base transistor (BC548), it will forward bias the base-emitter junction and voltage flowing through this junction causes voltage to flow across the collector-emitter junction. When this happened, the signal green LED will light. The green LED shows the voltage are in normal condition and when there is a voltage across the emitter, it will trigger (turn ON) the triac (TIC206D). The triac is a three-terminal devices and they are called main terminal one (MT1), main terminal two (MT2) and a gate. On the operation mode, the device remains in the off-state until it reached or a positive gate trigger voltage $\left(\mathrm{V}_{\mathrm{GT}}\right)$ generated a gate current sufficient to trigger the device. Once triggered, the device continues to conduct until the current through it drop below a certain threshold value. When the device continues to conduct, relay will be energized and the relay used AC current to operate with $220 \mathrm{~V}$. The relay operates when there is a positive gate trigger voltage at the triac and the coil (input circuit) will be energized. When the triac have been trigger, the coil will be energized and this will allowed the voltage to go thru and ON the bulb.

\section{B. Results}

These analyses have been done in the electric power lab using variable power supply. This analysis have been divided to four part that is normal voltage condition, under voltage warning condition, under voltage failure condition and over voltage failure condition. The variable power supply for the normal voltage will be set to $240 \mathrm{VAC}$ and the voltage comparison will be set to $2.19 \mathrm{~V}$ in the potentiometer. This voltage comparator is have been set for input comparator as a Vin and it will compare with Vref. In the waveform analysis, shows that the waveform is in a ripple form and make the reading not constant. The reading from the multimeter and the reading from oscilloscope are slightly different. The reading in the oscilloscope are not constant because the main 


\section{International Journal of Engineering Applied Sciences and Technology, 2020 \\ Vol. 4, Issue 11, ISSN No. 2455-2143, Pages 59-62 \\ Published Online March 2020 in IJEAST (http://www.ijeast.com)}

input $\mathrm{AC}$ voltage for the circuit have been invert to $\mathrm{DC}$ voltage and this produce ripple in the oscilloscope.

The variable power supply for the under voltage warning condition will be adjusted until the yellow LED turn ON $(200 \mathrm{~V})$ and the voltage comparison will be change to $1.72 \mathrm{~V}$. This voltage comparator will be a new input comparator as Vin and it will compare with Vref and the output will be determine as positive or negative output. Table 3.1 shows about the analysis for the LM 339 comparator and table 3.2 shows about the analysis for the Dual Retriggerable Monostable Multivibrator (74HCT123).

Table 3.1: Voltage reading for LM 339 in different voltage condition

\begin{tabular}{|c|c|c|c|c|}
\hline $\begin{array}{c}\text { IC } \\
\text { LM399 } \\
\text { (Pin) }\end{array}$ & $\begin{array}{c}\text { Voltage } \\
\text { at } \\
\mathbf{2 4 0 V}\end{array}$ & $\begin{array}{c}\text { Voltage } \\
\text { at } \\
\mathbf{2 0 0 V}\end{array}$ & $\begin{array}{c}\text { Voltage } \\
\text { at } \\
\mathbf{1 8 5}\end{array}$ & $\begin{array}{c}\text { Voltage } \\
\text { at } \\
\mathbf{2 6 4 V}\end{array}$ \\
\hline 1 & 3.532 & 1.87 & 0.171 & 3.499 \\
\hline 2 & 3.454 & 4.35 & 3.549 & 0.6 \\
\hline 3 & 4.95 & 4.89 & 4.87 & 4.94 \\
\hline 4 & 2.192 & 1.720 & 1.629 & 2.443 \\
\hline 5 & 2.435 & 2.425 & 2.394 & 2.431 \\
\hline 6 & 1.832 & 1.844 & 1.789 & 1.82 \\
\hline 7 & 2.195 & 1.720 & 1.629 & 2.443 \\
\hline 8 & 1.671 & 1.557 & 1.648 & 1.657 \\
\hline 9 & 2.196 & 1.722 & 1.628 & 2.44 \\
\hline 10 & 2.482 & 2.469 & 2.422 & 2.470 \\
\hline 11 & 2.497 & 2.471 & 2.428 & 2.47 \\
\hline 12 & 0 & 0 & 0 & 0 \\
\hline 13 & 2.480 & 2.455 & 2.425 & 2.465 \\
\hline 14 & 4.133 & 4.32 & 1.18 & 3.627 \\
\hline
\end{tabular}

In the analysis for the under voltage, the variable power supply will be adjusted until the red LED turn ON (185 VAC) and voltage comparison drop to $1.629 \mathrm{~V}$. This voltage comparator will be a new input comparator as Vin and it will compare with Vref and the output will be determine as positive or negative output. The red LED show that the power supplies have been under voltage condition and the circuit will trigger the dual retriggerable monostable multivibrator.

Analysis of over voltage condition, the variable power supply was adjusted to above $240 \mathrm{VAC}$ until the red LED turn ON (264 VAC) and voltage comparison increase to $2.443 \mathrm{~V}$. This voltage comparator will be a new input comparator as Vin and it will compare with Vref and the output will be determine as positive or negative output. The red LED show that the power supplies have been under voltage condition and the circuit will trigger the dual retriggerable monostable multivibrator.
Table 3.2: Voltage reading for 74HCT123 in different voltage condition

\begin{tabular}{|c|c|c|c|c|}
\hline $\begin{array}{c}\text { IC } \\
\text { ICT123 } \\
\text { (Pin) }\end{array}$ & $\begin{array}{c}\text { Voltage } \\
\text { at } \\
\mathbf{2 4 0 V}\end{array}$ & $\begin{array}{c}\text { Voltage } \\
\mathbf{a t} \\
\mathbf{2 0 0 V}\end{array}$ & $\begin{array}{c}\text { Voltage } \\
\mathbf{a t} \\
\mathbf{1 8 5}\end{array}$ & $\begin{array}{c}\text { Voltage } \\
\mathbf{a t} \\
\mathbf{2 6 4 V}\end{array}$ \\
\hline 1 & 4.60 & 4.26 & 0.593 & 0.605 \\
\hline 2 & 2.480 & 2.455 & 2.425 & 2.465 \\
\hline 3 & 4.61 & 4.28 & 4.28 & 4.45 \\
\hline 4 & 4.60 & 4.27 & 0 & 0 \\
\hline 5 & 0 & 0 & 0 & 0 \\
\hline 6 & 0 & 0 & 0 & 0 \\
\hline 7 & 4.61 & 4.27 & 4.21 & 4.37 \\
\hline 8 & 0 & 0 & 0 & 0 \\
\hline 9 & 4.59 & 4.24 & 0.6 & 0.603 \\
\hline 10 & 4.60 & 4.25 & 0 & 0 \\
\hline 11 & 4.61 & 4.26 & 4.21 & 4.41 \\
\hline 12 & 4.61 & 4.29 & 4.34 & 4.43 \\
\hline 13 & 0 & 0 & 4.34 & 4.46 \\
\hline 14 & 0 & 0 & 0 & 0 \\
\hline 15 & 4.61 & 4.34 & 1.161 & 1.183 \\
\hline 16 & 4.61 & 4.35 & 4.30 & 4.50 \\
\hline
\end{tabular}

\section{CONCLUSION}

The 'protection against under voltage or over voltage' circuits are able to reduce the damage on the load by protecting the equipment against under voltage and over voltage. This circuit also has the capability to switch off the power supply upon detection of under voltage or over voltage condition.

Although the 'protection against under voltage or over voltage' circuit cut-off the under voltage and over voltage conditions, some of the problem arise when the circuit is been tested. One of the problem arise is the triggering range using the dual retriggering monostable multivibrator for the under voltage warning condition, under voltage failure condition and over voltage failure condition have not been accurate at the time and output is not constant. This problem can be overcome by using the voltage divider method at the input reference (Vref) and choose the right value resistor [6]. This voltage divider method used to set the right value at the Vref so it can be compare with the input voltage (Vin) and trigger the dual retriggerable monostable multivibrator. Other problem arise is about the setting of the value for the voltage comparison in potentiometer and this problem make the output comparison between input voltage (Vin) and reference voltage (Vref) is not accurate. This potentiometer need to be adjusted until the input voltage comparison is set to 2.19 volt for normal voltage condition. This 2.19 volt is the intermediate value between the maximum and minimum value at the potentiometer. 
The analysis also shows that output waveform from the comparator is not a square wave but it is in a ripple form. This happened because the main AC sources have been converting to DC source before it has been connected to the comparator [5]. This waveform does not disturb the operation of the circuit and it triggers when there is an unbalance voltage in the $\mathrm{AC}$ line. The circuit automatically resets a switch and reconnects the line voltage when the $\mathrm{AC}$ line returns to nominal level.

\section{REFERENCE}

[1] Arrillaga, J., Watson, N. R., \& Chen, S. (n.d.). Power system quality assessment. Chichester, UK: John Wiley \& Sons, 2000 (Rep. 2001).

[2] Dugan, M, McGranaghan, A., and Beaty, H. (2012). electrical power systems quality, 3rd edition, McGraw- Hill, New-York,

[3] H. Ungrad, W. Winkler, A. Wiszniewski (1995). "Protection Techniques in Electrical Energy Systems." New York: Marcel Deklaer, Inc.

[4] J. Schlabbach, D. Blume, T. Stephanblome (2001). "Voltage Quality in Electrical Power System." United Kingdom: The Institution of Electrical Engineers.

[5] Ungrad, H., Winkler, W., \& Wiszniewski, A. (1995). Protection techniques in electrical energy systems. New York: Dekker.

[6] Ungrad. (2019). Protection Techniques In Electrical Energy Systems. S.1.: CRC PRESS.

[7] Power Quality. (2008). Power Quality, 1-25. doi: 10.1201/9781420064827.ch1 